\title{
LICENCIAMENTO AMBIENTAL NOS ESTADOS BRASILEIROS: OS PROCEDIMENTOS SERIAM OS MESMOS PARA UMA RODOVIA?
}

\author{
ENVIRONMENTAL LICENSING IN BRAZILIAN STATES: WOULD THE PROCEDURES BE THE \\ SAME FOR A HIGHWAY?
}

Thereza Isabelle Silva dos Santos ${ }^{a}$, Thayla Francisca Vilas Boas ${ }^{a}$, Patricia Ferreira ${ }^{a}$, Aline Carvalho Ribeiro ${ }^{a}$, Maria Rita Raimundo e Almeida ${ }^{a}$

a Universidade Federal de Itajubá

isabellesilsanthei@hotmail.com, thaylavilasboas@unifei.edu.br, patriciaferreira@unifei.edu.br, alineacr30@gmail.com, mrralmeida@unifei.edu.br.

Submissão: 10 de agosto de 2021

Aceitação: 02 de dezembro de 2021

\section{Resumo}

Rodovias consistem em estruturas cuja importância é atribuída à capacidade de propiciar a circulação entre lugares de pessoas e carga. Empreendimentos desta tipologia impactam o ambiente de forma diferenciada de acordo com as características do projeto e do meio em que estão inseridos. Por isso, são consideradas atividades potencialmente causadoras de degradação ambiental, sendo assim, passíveis de Licenciamento Ambiental (LA) junto ao órgão ambiental competente. Frente à possibilidade legal de procedimentos diferenciados para cada estado, o artigo tem como objetivo comparar o processo de LA estadual de uma rodovia estadual hipotética com extensão de $50 \mathrm{~km}$ em sete estados brasileiros: Bahia, Espírito Santo, Minas Gerais, Paraná, Rio de Janeiro, Rio Grande do Sul e Tocantins. A metodologia aplicada envolveu análise documental e de conteúdo de legislações e da página eletrônica dos órgãos licenciadores estaduais, visando levantar e comparar informações e dados relacionados ao processo de LA. Levantou-se em cada estado o órgão ambiental, o conselho estadual de meio ambiente e a legislação norteadora do LA, assim como, a necessidade da Avaliação de Impacto Ambiental (AIA) e do Estudo de Impacto Ambiental (EIA) para a rodovia hipotética. Pode-se notar uma diferença na classificação do potencial poluidor e do porte da atividade nos diferentes estados, mas todos eles apontam para a necessidade de realização da AIA para a análise da viabilidade do empreendimento, porém, nem todos se atêm ao EIA como estudo ambiental, deixando possibilidade de estudos mais simplificados. Espera-se que as comparações e discussões realizadas neste artigo possam servir como orientação para o processo de melhoria do Licenciamento e Avaliação de Impacto Ambiental no Brasil.

Palavras-chave: avaliação de impacto ambiental; triagem; legislação; impacto ambiental; órgão licenciador.

\section{Abstract}

Highways consist of structures whose importance is attributed to the ability to provide circulation between places of people and cargo. This typology of enterprises affects the environment differently according to the characteristics of the project and the environmental in which they are inserted. Therefore, they are considered activities potentially causing environmental degradation, and therefore, subject to Environmental Licensing (EL) by the competent environmental agency. Faced with the legal possibility of different procedures for each state, the article aims to compare the state Environmental Licensing process of a hypothetical state highway with a length of $50 \mathrm{~km}$ in seven Brazilian states: Bahia, Espírito Santo, Minas Gerais, Paraná, Rio de Janeiro, Rio Grande do Sul and Tocantins. The methodology applied involved documental and content analysis of legislation and the website of licensing agencies, in order to gather and compare information and data of EL process. In each state, the environmental agency, the state environmental council and the legislation guiding the EL process were raised, as well as the need for an Environmental Impact Assessment (EIA) and an 
Environmental Impact Study (EIS) for the hypothetical highway. A difference can be noted in the classification of the polluting potential and the size of the activity in the different states. However, all states point to the need to carry out the EIA for the analysis of the project's environmental feasibility. However, not all of them adhere to the EIS as an environmental study, leaving the possibility of more simplified studies. We hope that the comparisons and discussions carried out in this article can serve as a guide for the process of improving Environmental Licensing and Environmental Impact Assessment in Brazil.

Keywords: environmental impact assessment; screening; impact assessment; environmental agency.

\section{INTRODUÇÃO}

O Licenciamento Ambiental apresenta-se no sistema de desenvolvimento socioeconômico brasileiro atual como instrumento de política ambiental preventivo, destinado ao gerenciamento e controle de atividades e empreendimentos que utilizem dos recursos naturais e que podem vir a ocasionar degradação ambiental. Ele é um procedimento administrativo, pelo qual o órgão ambiental competente licencia a localização, instalação, ampliação e a operação de novos empreendimentos que podem de alguma forma ocasionar alterações e impactos ao meio ambiente (CONAMA, 1997). O mesmo constitui-se como instrumento de gestão, pelo qual o poder público consegue controlar as atividades humanas que empregam recursos naturais e provocam modificações nas condições ambientais (COSTA; MARTINS; PEGADO, 2009).

O modo como os procedimentos associados ao Licenciamento Ambiental ocorre depende da complexidade do empreendimento ou atividade e do seu potencial de causar impacto ao ambiente. A princípio, atividades consideradas de significativo impacto ambiental possuem seu Licenciamento Ambiental apoiado em uma Avaliação de Impacto Ambiental (AIA) e atividades que não causam impactos significativos ao meio caracterizam um Licenciamento Ambiental simplificado (SÁNCHEZ, 2020).

No Brasil, a Avaliação de Impacto Ambiental foi introduzida pela Lei Federal $n^{\circ}=6.938 / 1981$ (BRASIL, 1981), instituindo-se como um instrumento da Política Nacional de Meio Ambiente (PNMA). A Resolução Conama no 001/1986 estabelece os critérios e diretrizes para a AIA com a presença do estudo de impacto ambiental (EIA) e seu respectivo relatório de impacto ambiental (RIMA) (BELTRÃO, 2008). Moreira (1985) define a AIA como sendo formada por um conjunto de procedimentos que permitem assegurar que determinado projeto com possível potencial de causar impacto, tenha uma análise sistemática dos seus impactos, de modo que estes sejam apresentados ao público e sejam considerados nos processos de tomada de decisão, a fim de minimizar a ação antrópica sobre o meio ambiente. É um mecanismo de proteção nacional, que tem como objetivo avaliar previamente os impactos decorrentes da instalação de atividades consideradas poluidoras e consiste em uma das etapas para a concessão da licença ambiental (SANTOS, 2013). Ainda, a AIA como instrumento da PNMA assume significativa importância para a gestão de planos, programas e projetos em todas as competências, sejam nas esferas municipal, estadual ou federal (MOREIRA, 1985).

A Lei Complementar no 140/2011 define e distribui a competência do Licenciamento Ambiental de empreendimentos e atividades entre a União, os Estados, o Distrito Federal e os Municípios. De acordo com essa lei, é definida como competência Estadual o Licenciamento Ambiental de atividades ou empreendimentos que sejam localizados em unidades de conservação instituídas pelo Estado, excluídas as Áreas de Proteção Ambiental (APA) e as atividades que não se encaixam na competência da União (Art $7^{\circ}$ ) e nem dos municípios (Art. $9^{\circ}$ ) (BRASIL, 2011).

Em âmbito estadual, a legislação permite processos diferenciados de Licenciamento Ambiental, de modo que cada estado possui suas próprias regras e normas: o órgão ambiental competente possui autonomia para estabelecer, os procedimentos específicos para o processo de Licenciamento Ambiental, de acordo com as características e particularidades de cada empreendimento (CONAMA, 1997). Logo, é importante entender como o LA ocorre em cada estado.

Rodovias são um exemplo de empreendimentos que são licenciados no âmbito estadual, desde que possuam toda sua extensão em um único estado. Elas consistem em estruturas cuja importância é atribuída à capacidade de propiciar a circulação entre lugares e permitir o 
deslocamento de pessoas e cargas (BANDEIRA; FLORIANO, 2004). Por outro lado, 0 empreendimento viário causa impactos ambientais positivos e negativos aos três meios: biótico, físico e socioeconômico (SIMONETTI, 2010). No meio físico, os impactos estão relacionados à instabilidade de cortes e talude, e alagamentos devido a retirada da cobertura vegetal e a má execução do sistema de drenagem na rodovia (SIMONETTI, 2010). Os impactos gerados são relacionados a estabilidade dos solos, os quais implicam em processos erosivos, a qualidade do ar (emissão de poluentes e concentração de material particulado), qualidade da água, ruídos, alteração da paisagem, impactos sobre a fauna e flora, entre outros (BANDEIRA; FLORIANO, 2004). No meio biótico, os impactos são, na maioria das vezes, relacionados a atropelamentos de animais na pista, que também consequentemente, podem acarretar situações de perigo aos motoristas (SIMONETTI, 2010). Por fim, no meio socioeconômico, os impactos incidem nas alterações das atividades socioeconômicas (SIMONETTI, 2010). Ainda, para identificar, prever e avaliar os impactos ambientais de um projeto de rodovia, é usual decompor o empreendimento nas diversas fases de seu ciclo de vida, quais sejam, planejamento, implantação, operação e desativação (SÁNCHEZ, 2000). Fogliatti et al. (2004) destacam que na fase de implantação de uma rodovia os principais impactos são decorrentes da desapropriação, da implantação dos canteiros de obras, dos desmatamentos e limpeza dos terrenos, da abertura dos caminhos de serviço, da terraplanagem, do empréstimo e de bota-fora, da drenagem e da exploração de materiais de construção; já os decorrentes da operação são, em geral, menos significativos se comparados aos da implantação.

Assim, as rodovias são consideradas atividades modificadoras do ambiente, as quais, segundo as normas federais, estão sujeitas ao processo de Licenciamento Ambiental submetidas à elaboração do Estudo de Impacto Ambiental, e respectivo Relatório de Impacto Ambiental (EIA/RIMA) (CONAMA, 1986). Bandeira e Floriano (2004) explicam melhor essa informação afirmando que, em específico, rodovias que possuem duas ou mais faixas de rolamento, podendo estas, ser de domínio federal, a maioria estaduais e algumas municipais, deverão ser obrigatoriamente objeto de EIA/RIMA.

Diante do fato de que os sistemas rodoviários compreendem empreendimentos que impactam o meio ambiente $\mathrm{e}$ da possibilidade de procedimentos diferenciados em cada estado, o presente artigo tem como objetivo comparar o processo de Licenciamento Ambiental estadual de uma rodovia com extensão de $50 \mathrm{~km}$ em sete estados do Brasil.

\section{METODOLOGIA}

A metodologia utilizada neste trabalho teve como base a análise documental e de conteúdo, objetivando levantar informações e dados relacionados ao processo de Licenciamento Ambiental de rodovias nos estados brasileiros. Ao todo, foram estudados sete estados: Bahia, Espírito Santo, Minas Gerais, Paraná, Rio de Janeiro, Rio Grande do Sul e Tocantins.

A opção por utilizar as informações presentes na página eletrônica dos órgãos ambientais licenciadores, apesar de restrições e implicações nos resultados, possibilitou a realização desta pesquisa. Essa opção se baseia no fato de que a transparência e os controles informatizados têm sido repetidamente destacados na literatura como uma prática fundamental para administrações públicas eficientes, sobretudo em processos que envolvem múltiplas partes interessadas (SNELLEN; THAENS; DONK, 2012). As páginas eletrônicas dos órgãos ambientais licenciadores evoluíram substancialmente nos últimos anos, de modo que constituem hoje uma das mais importantes fontes de informação sobre a prática da Avaliação de Impacto Ambiental e do Licenciamento Ambiental no Brasil e, apesar de limitações, permitem a identificação e comparação de uma série de controles que podem servir de inspiração e subsídio de aprendizado e pesquisa (FONSECA; RESENDE, 2016). Os estados usados nesta pesquisa, segundo Fonseca e Resende (2016), se enquadram como bom ou razoável no percentual de atendimento de boas práticas de disponibilização de conteúdo em suas páginas eletrônicas.

Para cada um dos estados, escolhidos aleatoriamente e pela facilidade de obter informações na página eletrônica do órgão ambiental licenciador, foram listadas informações referentes aos órgãos licenciadores, conselho do meio ambiental e a principal legislação que orienta o processo de Licenciamento Ambiental no estado vigente em março de 2021. Todos os dados foram encontrados por meio das páginas eletrônicas dos órgãos estaduais licenciadores que compuseram 
um quadro comparativo de resultados.

Com o intuito de nortear a comparação do processo de Licenciamento Ambiental de cada estado, foi considerado o caso de rodovia estadual. Para enquadramento em cada legislação, a extensão da hipotética rodovia foi adotada como 50 km. Feitas essas considerações, o Licenciamento Ambiental da rodovia foi descrito para cada um dos estados, de acordo com a legislação em vigor, sendo destacados dois pontos de análise e comparação: a necessidade ou não da realização da Avaliação de Impacto Ambiental e qual estudo deveria ser desenvolvido no processo. Ao usar estes pontos de análise e comparação foi possível levantar os critérios e suas possibilidades de classificação usados nas legislações, como porte, classe, entre outros. Para complementar, foram utilizadas algumas referências bibliográficas de livros, manuais e artigos, assim como documentos virtuais, para auxiliarem no entendimento do Licenciamento Ambiental em cada estado.

\section{RESULTADOS E DISCUSSÃO}

Inicialmente, buscou-se a caracterização do quadro institucional e legal do Licenciamento Ambiental nos sete estados estudados (Quadro 1). Por esse quadro, percebe-se que cada estado possui sua própria legislação, o que se justifica frente à legislação federal: ao órgão ambiental competente cabe estabelecer quais serão as exigências ambientais específicas para 0 Licenciamento da atividade ou empreendimento, levando em consideração as especificidades, os riscos ambientais, o porte e outras características (CONAMA, 1997). Ainda cabe destacar o papel dos conselhos como órgãos responsáveis por estabelecer os procedimentos do Licenciamento Ambiental nos estados: com exceção da Bahia e do Espírito Santo, nos demais estados, foi o conselho estadual que editou a principal legislação orientadora do processo de Licenciamento ambiental. Justificável já que o Conselho Estadual de Meio Ambiente é um órgão colegiado, que existe para assessorar e propor ao estado o direcionamento das políticas para a preservação do meio ambiente e dos recursos naturais (INEA, 2015); e dentro da competência dos conselhos estaduais, assim como do Conselho Nacional de Meio Ambiente (CONAMA), estão a criação de normas e determinação de padrões compatíveis com o meio ambiente ecologicamente equilibrado e a qualidade de vida, já que são órgãos consultivos e deliberativos (BRASIL, 1981).

Uma vez entendido o quadro institucional e legal do licenciamento, buscou-se descrever os resultados de como seria o processo de Licenciamento Ambiental em cada estado.

Na Bahia, de acordo com o Decreto Estadual no 15682/2014, a classificação de empreendimentos e atividades engloba classes de 1 a 6 , de acordo com o porte e potencial poluidor, que variam entre pequeno, médio e grande (BAHIA, 2014). No mesmo decreto, com base no Anexo referente a tipologia e porte dos empreendimentos sujeitos ao Licenciamento Ambiental, a construção de uma rodovia de $50 \mathrm{~km}$ de extensão encaixa-se nas obras civis, divisão $F$, e classifica-se em "Complexos Viários Implantação ou Ampliação de estradas, pontes e afins" com porte pequeno $(P)$ e potencial poluidor alto $(A)$, classe 4; portanto, compreende um empreendimento de médio impacto ambiental (MMA, 2018). Por isso, o tipo de LA a ser requerido envolve a obtenção da Licença Prévia (LP), da Licença de Instalação (LI) e da Licença de Operação (LO); e não apenas a obtenção de uma licença unificada, como nos casos de empreendimentos de classes 1 ou 2 (BAHIA, 2014). Ainda, torna-se necessária a realização de AIA para empreendimentos de médio porte, contando com a presença do Estudo Ambiental para Atividades de Médio Impacto (EMI), realizado pelo empreendedor na etapa de LP, de acordo com o Termo de Referência elaborado pelo INEMA (MMA, 2018). Além disso, a Lei Estadual $\mathrm{n}^{\circ}$ 12.377/2011 instituiu como modalidade de licenciamento a Licença Ambiental por Adesão e Compromisso (LAC) concedida eletronicamente para empreendimentos de pequeno e médio portes que estejam listados na Resolução CEPRAM n 4.260/2012 (CEPRAM, 2012), o que não se aplica ao caso em análise de uma rodovia de $50 \mathrm{Km}$.

No Espírito Santo, a fim de licenciar o empreendimento, também se tem a necessidade prévia de enquadrá-lo segundo a magnitude do impacto. Para isto, considera-se o porte do empreendimento e o potencial degradador da obra. No caso em análise, o empreendimento encaixa-se em potencial poluidor degradador da obra é alto e porte grande, devido à sua extensão, de acordo com a Instrução Normativa IEMA no 014-N/2016 (IEMA, 2016). Para o enquadramento, não se considera o critério locacional, entretanto, tem-se na Instrução Normativa IEMA nº 05/2010 a 
ressalva à consideração de traçados alternativos em regiões de "preservação permanente, reservas legais, recursos hídricos, fragmentos florestais significativos, unidades de conservação, sítios arqueológicos, reservas indígenas e patrimônio histórico e natural" (IEMA, 2010). Feito o enquadramento, que pode ser consultado de forma on-line pelo site do órgão licenciador, é possível, por fim, ter a modalidade de licenciamento a ser solicitada. No estado capixaba, as modalidades de licenciamento são divididas em 27 tipos, dentre os quais encontra-se o licenciamento simplificado para as atividades que apresentam baixo impacto ambiental, autorizações ambientais, outorga e diferentes licenças (IEMA, 2016). Para o caso de uma rodovia de $50 \mathrm{~km}$ de extensão, a modalidade de licenciamento é dita como Licenciamento Ambiental Ordinário, mediante requerimento das LP, LI e LO (ou Licença Ambiental de Regularização, dependendo da fase em que se encontra). No que diz respeito ao estudo ambiental, para trechos com mais de $5 \mathrm{~km}$ de extensão caberá a apresentação de EIA/RIMA (Art. $8^{\circ}$ ) (IEMA, 2010).

\section{Quadro 1: Quadro institucional e legal do Licenciamento Ambiental nos estados}

\begin{tabular}{|c|c|c|c|}
\hline Estado & Órgão licenciador & $\begin{array}{l}\text { Conselho Estadual de Meio } \\
\text { Ambiente }\end{array}$ & $\begin{array}{l}\text { Principal legislação } \\
\text { orientadora }\end{array}$ \\
\hline Bahia & $\begin{array}{l}\text { Instituto do Meio Ambiente e } \\
\text { Recursos Hídricos (INEMA) }\end{array}$ & $\begin{array}{l}\text { Conselho Estadual do Meio } \\
\text { Ambiente (CEPRAM) }\end{array}$ & $\begin{array}{l}\text { Decreto Estadual } \mathrm{n}^{\circ} \\
15682 / 2014\end{array}$ \\
\hline Espírito Santo & $\begin{array}{l}\text { Instituto Estadual de Meio } \\
\text { Ambiente e Recursos Hídricos } \\
\text { (IEMA) }\end{array}$ & $\begin{array}{l}\text { Conselho Estadual de Meio } \\
\text { Ambiente } \quad \text { (CONSEMA) } \\
\text { Conselhos Regionais de Meio } \\
\text { Ambiente (CONREMAS) }\end{array}$ & $\begin{array}{l}\text { Instrução Normativa } \\
\text { IEMA no } 5 / 2010\end{array}$ \\
\hline Minas Gerais & $\begin{array}{lr}\text { Superintendência } & \text { de } \\
\text { Regularização } & \text { Ambiental } \\
\text { (SUPRAM) } & \end{array}$ & $\begin{array}{l}\text { Conselho Estadual de Política } \\
\text { Ambiental (COPAM) e as } \\
\text { Unidades Regionais Colegiadas } \\
\text { (URC) }\end{array}$ & $\begin{array}{l}\text { Deliberação Normativa } \\
\text { COPAM n² } 217 / 2017\end{array}$ \\
\hline Paraná & Instituto Água e Terra (IAT) & $\begin{array}{l}\text { Conselho Estadual do Meio } \\
\text { Ambiente do Paraná (CEMA) }\end{array}$ & $\begin{array}{l}\text { Resolução CEMA } \mathrm{n}^{\circ} \\
107 / 2020\end{array}$ \\
\hline Rio de Janeiro & $\begin{array}{l}\text { Instituto Estadual do Ambiente } \\
\text { (INEA) }\end{array}$ & $\begin{array}{l}\text { Conselho Estadual do Meio } \\
\text { Ambiente (CONEMA) }\end{array}$ & $\begin{array}{l}\text { Resolução CONEMA no } \\
42 / 2012\end{array}$ \\
\hline $\begin{array}{l}\text { Rio Grande do } \\
\text { Sul }\end{array}$ & $\begin{array}{l}\text { Fundação Estadual de Proteção } \\
\text { Ambiental Henrique Luíz Roessler } \\
\text { (FEPAM) }\end{array}$ & $\begin{array}{l}\text { Conselho Estadual do Meio } \\
\text { Ambiente (CONSEMA) }\end{array}$ & $\begin{array}{l}\text { Resolução CONSEMA no } \\
372 / 2018\end{array}$ \\
\hline Tocantins & $\begin{array}{l}\text { Instituto Natureza do Tocantins } \\
\text { (Naturatins) }\end{array}$ & $\begin{array}{l}\text { Conselho Estadual do Meio } \\
\text { Ambiente (COEMA) }\end{array}$ & $\begin{array}{l}\text { Resoluções COEMA no } \\
7 / 2005 \text { e } n^{0} \text { 8/2005 }\end{array}$ \\
\hline
\end{tabular}

Fonte: As autoras (2021).

Em Minas Gerais, o processo de Licenciamento Ambiental é regulamentado, entre outras normas legais, pela Deliberação Normativa COPAM n² 217/2017. Esta legislação regulamenta a definição da modalidade do Licenciamento Ambiental, baseada no potencial poluidor/degradador da atividade (pequeno, médio ou grande), no porte (pequeno, médio ou grande) e no peso do critério locacional $(0,1$ ou 2$)$
(COPAM, 2017). Para uma rodovia de $50 \mathrm{~km}$ de extensão, o potencial poluidor degradador é grande e o porte médio, o que a classifica como um empreendimento classe 5 (conforme listagem E do Anexo Único da Deliberação Normativa COPAM $n^{\circ}$ 217/2017). Para um empreendimento classe 5, o licenciamento pode ser da modalidade de Licenciamento Ambiental Concomitante (LAC) do tipo 2 (LAC2) ou Licenciamento Ambiental 
Trifásico (LAT), a depender do fator locacional. O LAT é Licenciamento no qual LP, LI e LO da atividade ou do empreendimento são concedidas em etapas sucessivas; e o LAC é Licenciamento no qual são analisadas as mesmas etapas previstas no LAT, com a expedição de duas ou mais licenças concomitantemente (MINAS GERAIS, 2018). No LAC2, a emissão das LP e LI ocorre em uma única fase e, posteriormente, a LO; ou com emissão da LP e, na sequência, da LI e LO concomitante (MINAS GERAIS, 2018). Como as possibilidades de localização da rodovia de $50 \mathrm{~km}$ são grandes, a consideração realizada foi de que o licenciamento poderia ser um LAC 2 ou LAT. Tanto o LAC como o LAT são modalidades de Licenciamento Ambiental que envolvem a AIA, devendo ser elaborado como estudo na fase de LP o EIA/RIMA ou o Relatório de Controle Ambiental (RCA), solicitado quando da dispensa do EIA. No entanto, na legislação mineira, não fica claro em que situações ou a partir de quais critérios a dispensa do EIA poderá se dar, indicando que essa decisão continua sendo baseada na discricionariedade do órgão ambiental (ALMEIDA; MALVESTIO; BERNADI, 2019).

Os critérios gerais de Licenciamento Ambiental no estado do Paraná são definidos pela Resolução CEMA no 107/2020 que dispõe sobre o Licenciamento e estabelece os procedimentos a serem adotados para as atividades poluidoras, degradadoras e modificadoras do meio ambiente. A definição da modalidade do Licenciamento é baseada no potencial poluidor/degradador (pequeno, médio ou grande), no porte (mínimo, pequeno, médio, grande ou excepcional) e na localização da atividade, sendo o enquadramento dos empreendimentos e atividades em classes estabelecido pelo órgão ambiental competente conforme matriz de conjugação do potencial poluidor/degradador e do porte (CEMA, 2020). A implantação de novos empreendimentos viários terrestres no estado requer a obtenção da LP, LI e LO, sendo exigida a apresentação de Relatório Ambiental Simplificado (RAS) para rodovias com extensão de até $50 \mathrm{~km}$. Entretanto, caso o empreendimento extrapole a faixa de domínio acarretando remoção de população, transposição em Unidades de Conservação de Proteção Integral, intervenção em bens culturais acautelados ou em cavidades naturais subterrâneas, supressão de vegetação nativa primária ou secundária, em estágio avançado de regeneração ou interfira em áreas de fragilidade ambiental será exigida a apresentação de
EIA/RIMA (CEMA, 2015). Ainda, segundo o Art. 59ํㅁ da Resolução CEMA no 107/2020, rodovias primárias e autoestradas (com duas ou mais faixas de rolamento) e rodovias secundárias, vicinais e variantes que atravessem áreas prioritárias para a conservação, legalmente instituídas, são obras consideradas de significativo impacto ambiental, portanto, dependerão de elaboração de EIA/RIMA a ser submetido à aprovação do órgão ambiental competente (CEMA, 2020).

No Rio de Janeiro, o art. $2^{\circ}$ da Resolução CONEMA no 42/2012 enquadra as atividades sujeitas ao Licenciamento Ambiental em classes de magnitude do impacto ambiental, com base no potencial poluidor (insignificante, baixo, médio ou alto) e porte das atividades ou empreendimentos (mínimo, pequeno, médio, grande ou excepcional) (CONEMA, 2012). Segundo a Resolução INEA № $52 / 2012$, a construção de uma rodovia de $50 \mathrm{~km}$ se enquadra em obras lineares - vias e dutos e deve ser licenciada (INEA, 2012). O potencial poluidor para a rodovia é alto (INEA, 2012) e porte médio (INEA, 2011). Para a rodovia de potencial poluidor alto e porte médio, tem-se uma classificação de alto impacto classe 5 (Impacto Alto Classe 5A) (CONEMA, 2012). Sendo assim, o empreendimento, por ser classe 5, precisa apresentar em seu Licenciamento o EIA para obter a LP.

No Rio Grande do Sul, o processo de Licenciamento Ambiental é realizado de acordo com a classificação de porte e potencial poluidor do empreendimento. $O$ porte apresenta 5 classificações, sendo: mínimo, pequeno, médio, grande porte ou excepcional. Já o potencial poluidor pode ser alto, médio ou baixo. Uma rodovia de $50 \mathrm{~km}$ apresenta porte excepcional e potencial poluidor alto, segundo o Anexo I da Resolução CONSEMA nำ 372/2018 (CONSEMA, 2018), implicando assim, em um Licenciamento Ambiental realizado pelo Estado (e não municipal). A Resolução CONSEMA no 372/2018 não trata sobre os estudos necessários para o LA. No entanto, segundo o Art. 69을 Lei Estadual $\mathrm{n}^{\circ}$ 15.434/2020, que institui o Código Estadual do Meio Ambiente do Estado do Rio Grande do Sul e dá outras providências, o licenciamento de empreendimentos ou atividades considerados de significativo potencial de impacto ambiental dependerá da apresentação do EIA/ RIMA, sendo que a caracterização dos mesmos dependerá, para cada um de seus tipos, de critérios a serem definidos pelo órgão ambiental competente e fixados normativamente pelo Conselho Estadual 
do Meio Ambiente, respeitada a legislação federal (RIO GRANDE DO SUL, 2020). Embora a legislação não seja clara, visto que uma rodovia de $50 \mathrm{~km}$ é classificada pela legislação como de porte excepcional e alto potencial poluidor, as autoras consideraram que a mesma possui um significativo potencial poluidor, sendo, portanto, necessário 0 EIA/RIMA.

Para o estado do Tocantins, a classificação dos empreendimentos, obras e atividades passíveis de Licenciamento Ambiental é descrita no Anexo I da Resolução COEMA/TO no 8/2005 (COEMA, 2005b), que define 14 grupos de atividades, em função das peculiaridades e especificidades. Cada grupo é subdividido de acordo com as características, riscos ambientais e porte. Quanto à classificação do porte, as atividades podem ter três classificações distintas, em conformidade com seu grupo de atividade: pequeno, médio ou grande. Ainda de acordo com o Anexo I da referida resolução (COEMA, 2005b), a construção de rodovias enquadra-se na categoria "Obras Civis Lineares", sendo um empreendimento classificado como de porte médio. Para o LA de obras civis lineares, como rodovias de $50 \mathrm{~km}$, a Resolução COEMA/TO no 7/2005 (COEMA, 2005a) determina que 0 requerente deve solicitar a LP, LI e LO. No que diz respeito aos estudos ambientais, a Resolução COEMA/TO no 7/2005 (COEMA, 2005a) informa que dependerão da elaboração do EIA/RIMA atividades citadas no art. $2^{\circ}$ da Resolução do CONAMA no 001/1986, como é o caso das estradas de rodagem com duas ou mais faixas de rolamento (CONAMA, 1986). Entretanto, destacase que a critério do órgão ambiental do estado do Tocantins outros estudos também podem ser solicitados, sendo estes descritos na Resolução COEMA/TO no 7/2005 (COEMA, 2005a), sendo que cada grupo de tipologias possui termos de referência para elaboração dos estudos ambientais, tendo sido formulados de acordo com seu porte (pequeno, médio ou grande) (MMA, 2016). Dentre os documentos solicitados para o Licenciamento Ambiental de obras civis lineares, como o caso de rodovias, é solicitado na licença prévia a apresentação do Projeto Ambiental (PA) ou Relatório de Controle Ambiental (RCA) ou o EIA/RIMA (COEMA, 2005a).

Uma vez descritas as modalidades de Licenciamento Ambiental e os estudos necessários para cada estado, o Quadro 2 permite uma comparação destas informações.

Conceitualmente, o potencial de causar impacto depende da pressão que a tipologia do empreendimento e seu arranjo tecnológico exerce sobre os recursos naturais e da sensibilidade do local em que se pretende implantar o projeto (SÁNCHEZ, 2020). Consequentemente, a definição do que seria potencial de causar impacto significativo e, portanto, da necessidade da Avaliação de Impacto Ambiental, depende de características do projeto e do meio. Para Jones e Morrison-Saunders (2016), a determinação da significância do impacto está no cerne da AIA, mas conflitos e mal-entendidos em torno do conceito são comuns.

No caso deste artigo, a determinação do potencial de causar impacto e de sua significância é usada na etapa de triagem, que inclui procedimentos para determinar se a proposta deverá ou não estar sujeita à $A I A$, e em caso afirmativo, a que nível de detalhe (IAIA, 1999). A triagem representa uma fase crítica de decisão (WOOD; BECKER, 2005) e reflete o primeiro nível de compromisso do sistema de AIA com a proteção ambiental (RAJARAM; DAS, 2011).

A partir da análise do processo de Licenciamento Ambiental para a rodovia de $50 \mathrm{~km}$ nos diferentes estados, observou-se que tal empreendimento possui classificação quanto ao tipo de licenciamento de acordo com a legislação, sendo que, para todos os estados estudados, o porte e o potencial poluidor são as diretrizes norteadoras do tipo de Licenciamento Ambiental, apontando ou não para a necessidade de AIA. Rocha e Fonseca (2017), avaliando os estados da região Sudeste do Brasil, já haviam apontado que os critérios usados na triagem para avaliar a significância dos impactos eram baseados na tipologia, tamanho e potencial de poluição biofísica dos projetos.

Percebe-se, assim, que esses critérios de triagem refletem características apenas do projeto. Ressalva para os estados de Minas Gerais e, muito superficialmente, Espírito Santo, que consideram ainda em seu enquadramento os critérios locacionais que refletem características do meio. Para Almeida, Malvestio e Bernadi (2019), a introdução do critério locacional pode ser considerada como grande avanço da legislação mineira e, para Fonseca, Sánchez e Ribeiro (2017), introduzir fatores locacionais nos critérios de triagem está entre as principais prioridades para a modificação do sistema brasileiro de AIA na opinião de especialistas. Isso tudo porque o potencial de causar impacto depende da pressão que o empreendimento exerce sobre os recursos 
naturais e da sensibilidade do local em que se pretende implantar o projeto (SÁNCHEZ, 2020). Logo, um processo que observe somente para 0 empreendimento pode levar a uma triagem inadequada.

Em relação aos fatores que refletem características do projeto, verifica-se uma variação quanto à determinação do porte e do potencial poluidor nos estados. Em Minas Gerais, Rio de Janeiro e Tocantins, a atividade é considerada de porte médio, na Bahia porte pequeno e no Espírito
Santo e Rio Grande do Sul grande e excepcional, respectivamente. Considerando 0 potencial poluidor, a maioria dos estados classifica a atividade como alto (Minas Gerais denomina como grande), sendo que Paraná e Tocantins não deixam claro quanto à classificação do potencial poluidor. Para Sippe (1999), na ausência de uma definição conceitual legal, como a significância é tratada por diferentes jurisdições difere notavelmente.

\section{Quadro 2: Comparação do processo de Licenciamento Ambiental em cada estado para uma rodovia} de $50 \mathrm{~km}$ de extensão

\begin{tabular}{|l|l|l|l|l|l|}
\hline Estado & $\begin{array}{l}\text { Potencial } \\
\text { poluidor/ } \\
\text { degradador }\end{array}$ & Porte & Classe & $\begin{array}{l}\text { Precisa de } \\
\text { AIA? }\end{array}$ & Qual estudo? \\
\hline Bahia & Alto & Pequeno & Classe 4 & Sim & $\begin{array}{l}\text { Estudo Ambiental para Atividades de } \\
\text { Médio Impacto (EMI) }\end{array}$ \\
\hline Espírito Santo & Alto & Grande & - & Sim & EIA/RIMA \\
\hline Minas Gerais & Grande & Médio & Classe 5 & Sim & $\begin{array}{l}\text { RCA ou EIA/RIMA, sem critério de } \\
\text { definição }\end{array}$ \\
\hline Paraná & - & - & - & Sim & $\begin{array}{l}\text { RAS ou EIA/RIMA, a depender da } \\
\text { localização }\end{array}$ \\
\hline Rio de Janeiro & Alto & Médio & $\begin{array}{l}\text { Classe 5A (alto } \\
\text { impacto) }\end{array}$ & Sim & EIA/RIMA \\
\hline $\begin{array}{l}\text { Rio Grande do } \\
\text { Sul }\end{array}$ & Alto & Excepcional & - & Sim & EIA/RIMA \\
\hline Tocantins & - & Médio & - & Sim & PA, RCA ou EIA/RIMA \\
\hline
\end{tabular}

Fonte: As autoras (2021).

Almeida e Montaño (2012) avaliaram os sistemas de AIA e Licenciamento Ambiental dos estados do Ceará, Espírito Santo, Minas Gerais, Pará, Paraná, Pernambuco e Rio Grande do Sul. Apesar da adoção de terminologias diferentes, os estudos ambientais destinados a avaliar a viabilidade ambiental dos empreendimentos puderam ser agrupados em três categorias: o EIA/RIMA destinado a empreendimentos que tem o potencial de causar impactos significativos; estudos mais simplificados como o Relatório de Controle Ambiental (RCA) no Ceará, Espírito Santo, Minas Gerais e Pará e o Relatório Ambiental Preliminar (RAP) em Pernambuco, Paraná e São Paulo, destinados a empreendimentos cujo potencial de causar impacto é médio; e estudos ainda mais simples para empreendimentos com baixo potencial de causar impacto, como o Estudo Ambiental Simplificado (EAS) em São Paulo e Ceará e o Relatório Ambiental Simplificado (RAS) no Pará, Pernambuco, Paraná e Rio grande do Sul, ou até, apenas formulários e documentos como no Espírito Santo e Minas Gerais.

No caso deste estudo, apesar da necessidade da Avaliação de Impacto Ambiental para o Licenciamento Ambiental do empreendimento ser aplicada na grande maioria dos estados estudados, a BA utiliza como estudo o Estudo Ambiental para Atividades de Médio Impacto (EMI). O EMI é realizado na etapa de LP para empreendimentos Classes 3, 4 e 5, de acordo com 
- Termo de Referência elaborado pelo INEMA (MMA, 2018). Sob o mesmo contexto, três dos sete estados consideram apenas o EIA/RIMA como estudo envolvido no caso em questão. No entanto, Minas Gerais, Paraná e Tocantins também consideram o uso de outros estudos, sendo estes o Relatório de Controle Ambiental (RCA), Relatório Ambiental Simplificado (RAS) ou Projeto Ambiental (PA). O RCA em Minas Gerais visa à identificação dos aspectos e impactos ambientais inerentes às fases de instalação e operação da atividade e instruirão o processo de LP, conforme o caso (COPAM, 2017); já no Tocantins contém informações, levantamentos e ou estudos que permitam avaliar os efeitos do empreendimento sobre o meio ambiente abrangendo descrição do empreendimento, diagnóstico ambiental da área de influência do projeto, análise dos impactos ambientais e proposta de medidas mitigadoras, avaliação da ocorrência de acidentes e monitoramento ambiental (COEMA, 2005a). O RAS na Paraná é um estudo relativo aos aspectos ambientais relacionados à localização, instalação, operação e ampliação de uma atividade ou empreendimento, apresentados como subsídio para a concessão da LP, que conterá, dentre outras, as informações relativas ao diagnóstico ambiental da região de inserção do empreendimento, sua caracterização, a identificação dos impactos ambientais e das medidas de controle, de mitigação e de compensação (CEMA, 2020). Por fim, o PA no Tocantins contém de forma objetiva informações que permitam avaliar a viabilidade da implementação da atividade e ou empreendimento. Em resumo, são estudos cuja complexidade da avaliação de impacto é menor que o EIA, embora o conteúdo seja muito semelhante. Rocha e Fonseca (2017) denominam estes casos como processos de licenciamento com AIA simplificada. A questão que se levanta em relação à alternativa de utilização de outros estudos, é o quanto esses documentos são eficazes em relação ao EIA e quanto a efetividade da Avaliação de Impacto Ambiental pode ser comprometida por um estudo simplificado.

Oliveira et al. (2016) abordam sobre a temática ao analisar e comparar os conceitos e modelos de Licenciamento Ambiental estadual simplificado na região sudeste brasileira. Os autores evidenciam que a simplificação pode diminuir o grau de precaução do processo ao diminuir o volume de informações e ritos de análise e participação pública; todavia, os procedimentos simplificados podem agilizar a concessão de licença e reduzir os custos do processo (OLIVEIRA et al., 2016). É importante destacar que simplificar tem o sentido de tornar mais claro, menos complexo e o que se deve buscar para o Licenciamento Ambiental é um modelo normativo mais simples, sem diminuir, em nada, a segurança e eficiência do exame das externalidades ambientais negativas (GARBACCIO; SIQUEIRA; ANTUNES, 2018).

Ainda sobre a necessidade ou não do Estudo de Impacto Ambiental e respectivo Relatório de Impacto Ambiental, cabe destacar que a realização de audiência pública está associada apenas aos processos de Licenciamento Ambiental baseados em EIA/RIMA (CONAMA, 1986). A realização das audiências públicas é regulamentada pela Resolução CONAMA $n^{\circ} 09$, de 03 de dezembro de 1987 e tem por finalidade expor aos interessados o conteúdo do produto em análise e do seu referido RIMA, dirimindo dúvidas e recolhendo dos presentes as críticas e sugestões a respeito (CONAMA, 1987). Dentre os diversos objetivos da participação na AIA, Glucker et al. (2013) citam: influenciar decisões, aumentar a capacidade democrática, servir como aprendizado social, capacitar e emancipar grupos ou indivíduos marginalizados, aproveitar conhecimentos e informações locais, incorporar conhecimento experimental e baseado em valor, testar a robustez das informações de outras fontes, gerar legitimidade e resolver conflitos. Sendo assim, a simplificação do tipo de estudo também representa a redução ou ausência da participação pública no processo e 0 não cumprimento dos seus objetivos. Santos e Borges (2017), tomando como estudo o Licenciamento Ambiental de Minas Gerais, apontam que as mudanças legais trazidas pelas legislações mais atuais têm fragilizado o modelo participativo do Licenciamento Ambiental.

Em resumo, o processo de licenciamento ambiental dos estados estudados (Bahia, Espírito Santo, Minas Gerais, Paraná, Rio de Janeiro, Rio Grande do Sul e Tocantins) apresentaram variações em relação ao potencial poluidor, porte e classificação, implicando em estudos ambientais distintos, mas, em todos estes estados, o processo de Licenciamento Ambiental de uma rodovia de 50 $\mathrm{km}$ de extensão conta com 0 apoio da AIA. Resultado mais diverso foi encontrado por Rocha e Fonseca (2017) que revelaram diferenças mais significativas para o Licenciamento Ambiental de mineração de granito, estação de tratamento de 
esgoto e postos de gasolina, entretanto, bem semelhantes para hidrelétricas.

Em um contexto geral do processo de Licenciamento Ambiental estadual no Brasil, o mesmo constitui-se como um cenário heterogêneo, pois apesar da existência de instrumentos legais norteadores, os órgãos ambientais licenciadores possuem autonomia para definir os procedimentos e critérios a serem adotados durante o processo (MMA, 2016). As implicações práticas das diferenças de triagem expõem a existência de incentivos ou desincentivos "tácitos" para a instalação de projetos de desenvolvimento específicos em algumas regiões geográficas, podendo fornecer uma vantagem competitiva (ROCHA; FONSECA, 2017). No entanto, deve-se olhar com muito cuidado para as propostas de mudança legal sobre o Licenciamento, já que diversas proposições de alterações legislativas nem sempre estão preocupadas com a melhoria do seu desempenho e sua qualidade (LIMA; REI, 2017) e podem exacerbar ainda mais a degradação e as injustiças socioambientais no país (BORINELLI et al., 2020).

\section{CONSIDERAÇÕES FINAIS}

No que tange ao processo de Licenciamento Ambiental de rodovias, os órgãos ambientais de cada estado possuem autonomia para determinar seus próprios procedimentos e critérios e estes estão expressos nas normas legais de cada um. Tais procedimentos são realizados conforme as diferentes tipologias de obras rodoviárias, principalmente, segundo o porte e potencial poluidor que a atividade pode ocasionar ao meio ambiente, envolvendo, assim, apenas critérios associados ao projeto e sem levar em consideração as questões relacionadas ao meio que irá receber o empreendimento. Nesse sentido, os processos de licenciamento ambiental dos estados estudados apresentaram variações em relação ao potencial poluidor, porte e classificação, implicando em estudos ambientais distintos. No entanto, o processo de Licenciamento Ambiental de uma rodovia de $50 \mathrm{~km}$ de extensão em todos estes estados conta com o apoio da AIA.

As diferenças nos processos de Licenciamento Ambiental têm implicações que foram aqui discutidas, especialmente, ao poder gerar mecanismos de vantagem competitiva entre os estados e, devido a este fato, levar os órgãos licenciadores a serem cada vez mais permissivos.
Embora para o caso da rodovia de $50 \mathrm{~km}$ não tenha havido tanta discrepância nos procedimentos do Licenciamento Ambiental, é importante, mais que a padronização da triagem entre os estados, aperfeiçoar seus mecanismos, de modo a realizar a adequada separação de projetos que causam significativo impacto ambiental dos que não causam. Além disso, os mecanismos de triagem devem considerar, além das características do empreendimento (porte e potencial poluidor), elementos que permitam avaliar a sensibilidade do meio que vai receber 0 projeto (fator locacional).

Espera-se que as comparações e discussões realizadas neste artigo possam servir como orientação para o processo de melhoria do Licenciamento e Avaliação de Impacto Ambiental no Brasil.

\section{REFERÊNCIAS}

ALMEIDA, M. R. R.; MALVESTIO, A. C.; BERNADI, Y. $R$. Modificações do licenciamento ambiental em Minas Gerais: avanço ou retrocesso? Desenvolvimento e Meio Ambiente, v.52, p.91-113, 2019.

ALMEIDA, M. R. R.; MONTAÑO, M. Procedimentos de Avaliação de Impacto Ambiental e licenciamento no Brasil: semelhanças e diferenças dos sistemas estaduais. In: $1^{\circ}$ Congresso Brasileiro de Avaliação de Impacto, 2012, São Paulo. Anais... São Paulo: ABAI, 2012.

BAHIA. Decreto no 15682, de 19 de novembro de 2014. Altera o Regulamento da Lei o 10.431 , de 20 de dezembro de 2006 e da Lei no 11.612 , de 08 de outubro de 2009, aprovado pelo Decreto o 14.024, de 06 de junho de 2012. Diário Oficial do Estado, Salvador, 20 nov. $2014 . \quad$ Disponível em: https://www.legisweb.com.br/legislacao/?id=277304. Acesso em: 13 mar. 2021.

BANDEIRA, C.; FLORIANO, E. P. Avaliação de impacto ambiental de rodovias. Caderno Didático n. 8. 1 ed. Santa Rosa, 2004. 16p.

BELTRÃO, A. F. G. Aspectos jurídicos do estudo de impacto ambiental. São Paulo: MP Editora, 2008.

BORINELLI, B.; MOSTAG, N. C.; CORADO, B. F. S.; MELAN, R. L. Um sistema em colapso? Dificuldades dos sistemas de licenciamento ambiental dos estados brasileiros. In: SILVA, M. E. D. (org). Sustentabilidade: a superação de desafios para a manutenção do sistema. Ponta Grossa: Atena, 2020. p.72-84. 
BRASIL. Lei nำ6938, de 31 de agosto de 1981. Dispõe sobre a Política Nacional do Meio Ambiente, seus fins e mecanismos de formulação e aplicação, e dá outras providências. Diário Oficial da União, Brasília, 02 set. 1981 Disponível em: http://www.planalto.gov.br/ccivil_03/leis/16938.htm. Acesso em: 14 jan. de 2021.

BRASIL. Lei Complementar nํ 140, de 8 de dezembro de 2011. Fixa normas, nos termos dos incisos III, VI e VII do caput e do parágrafo único do art. 23 da Constituição Federal, para a cooperação entre a União, os Estados, o Distrito Federal e os Municípios nas ações administrativas decorrentes do exercício da competência comum relativas à proteção das paisagens naturais notáveis, à proteção do meio ambiente, ao combate à poluição em qualquer de suas formas e à preservação das florestas, da fauna e da flora; e altera a Lei no 6.938, de 31 de agosto de 1981. Diário Oficial da União, Brasília, 90 dez. 2011. Disponível em: http://www.planalto.gov.br/ccivil_03/leis/lcp/lcp140.htm. Acesso em: 14 jan. 2021.

CEMA. Conselho Estadual de Meio Ambiente. Resolução $n^{\circ} 46$, de 17 de junho de 2015. Estabelece requisitos, definições, critérios, diretrizes e procedimentos administrativos referentes ao Licenciamento Ambiental e Regularização Ambiental de empreendimentos viários terrestres, públicos e privados, a serem cumpridos no território do Estado do Paraná. Diário Oficial do Estado, Curitiba, 03 jul. 2015. Disponível em: https://www.legisweb.com.br/legislacao/?id=286517. Acesso em: 6 jul. 2021.

CEMA. Conselho Estadual de Meio Ambiente. Resolução $\mathrm{n}^{\circ}$ 107, de 09 de setembro de 2020. Dispõe sobre o licenciamento ambiental, estabelece critérios e procedimentos a serem adotados para as atividades poluidoras, degradadoras e/ou modificadoras do meio ambiente e adota outras providências. Diário Oficial do Estado, Curitiba, 17 set. $2020 . \quad$ Disponível em: https://www.legisweb.com.br/legislacao/?id=401593. Acesso em: 6 jul. 2021.

CEPRAM. Conselho Estadual do Meio Ambiente. Resolução no 4260, de 15 de junho de 2012. Dispõe, no âmbito do licenciamento ambiental, sobre os procedimentos e as atividades ou empreendimentos a serem licenciados por meio de Licença Ambiental por Adesão e Compromisso - LAC no Estado da Bahia. Diário Oficial do Estado, Salvador, 13 jul. 2012. Disponível em: https://www.legisweb.com.br/legislacao/?id=243283. Acesso em: 10 ago. 2021.

COEMA. Conselho Estadual do Meio Ambiente. Resolução $n^{\circ}$ 07, de 09 de agosto de 2015. Dispõe sobre o Sistema Integrado de Controle Ambiental do Estado do Tocantins Diário Oficial do Estado, Palmas, 9 set. 2005a. Disponível em: https://central3.to.gov.br/arquivo/512717/. Acesso em: 06 jul. 2021.

COEMA. Conselho Estadual do Meio Ambiente. Resolução $n^{\circ}$ 08, de 14 de dezembro de 2005. Altera os anexos I e III da Resolução $\mathrm{n}^{\circ} \mathbf{7}$, de 9 de agosto de 2005b. Diário Oficial do Estado, Palmas, 16 fev. 2006. Disponível em: https://supremoambiental.com.br/wpcontent/uploads/2018/08/resolucao-n-08-coema-2005altera-os-anexos-i-e-iii-da-resoluo-n-07-coema2005.pdf. Acesso em: 06 jul. 2021.

CONAMA. Conselho Nacional do Meio Ambiente. Resolução no 001, de 23 de janeiro de 1986. Dispõe sobre critérios básicos e diretrizes gerais para a avaliação de impacto ambiental. Diário Oficial da União, Brasília, 17 fev. 1986. Disponível em: http://www2.mma.gov.br/port/conama/res/res86/res018 6.html. Acesso em: 12 jan. 2021.

CONAMA. Conselho Nacional do Meio Ambiente. Resolução $n^{\circ}$ 9, de 3 de dezembro de 1987. Dispõe sobre a realização de Audiências Públicas no processo de licenciamento ambiental. Diário Oficial da União, Brasília, 05 jul. 1990. Disponível em: https://snif.florestal.gov.br/images/pdf/legislacao/resolu coes_conselho/resolucao_conama_09_1987.pdf.

Acesso em: 10 ago. 2021.

CONAMA. Conselho Nacional do Meio Ambiente. Resolução no 237, de 19 de dezembro de 1997. Dispõe sobre conceitos, sujeição, e procedimento para obtenção de Licenciamento Ambiental, e dá outras providências. Diário Oficial da União, Brasília, 22 dez. $1997 . \quad$ Disponível em: https://www.icmbio.gov.br/cecav/images/stories/downlo ads/Legislacao/Res_CONAMA_237_1997.pdf. Acesso em: 12 jan. 2021.

CONEMA. Conselho Estadual de Meio Ambiente do Rio de Janeiro. Resolução $n^{\circ}$ 42, de 17 de agosto de 2012. Dispõe sobre as atividades que causam ou passam causar impacto ambiental local, fixa normas gerais de cooperação federativa nas ações administrativas decorrentes do exercício da competência comum relativas à proteção das paisagens naturais notáveis, à proteção do meio ambiente e ao combate à poluição em qualquer de suas formas, conforme previsto na Lei Complementar n¹40/2011, e dá outras providências. Diário Oficial do Estado, Rio de Janeiro, 28 ago. 2012. Disponível

em: http://www.rio.rj.gov.br/dlstatic/10112/5063790/4186761 /Res_CONEMA_42_12.pdf. Acesso em: 21 jan. 2021.

CONSEMA. Conselho Estadual do Meio Ambiente. Resolução $n^{\circ} 372,22$ de fevereiro de 2018. Dispõe sobre os empreendimentos e atividades utilizadores de recursos ambientais, efetiva ou potencialmente 
poluidores ou capazes, sob qualquer forma, de causar degradação ambiental, passíveis de licenciamento ambiental no Estado do Rio Grande do Sul, destacando os de impacto de âmbito local para o exercício da competência municipal no licenciamento ambiental. Diário Oficial do Estado, Porto Alegre, 01 mar. 2018. Disponível em: https://www.sema.rs.gov.br/upload/arquivos/201909/17 101650-372-2018-atividades-licenciaveiscompilada.pdf. Acesso em: 22 jan. 2021.

COPAM. Conselho Estadual de Política Ambiental. Deliberação Normativa $n^{\circ} 217$, de 06 de dezembro de 2017. Estabelece critérios para classificação, segundo o porte e potencial poluidor, bem como os critérios locacionais a serem utilizados para definição das modalidades de licenciamento ambiental de empreendimentos e atividades utilizadores de recursos ambientais no Estado de Minas Gerais e dá outras providências. Diário Oficial do Estado, Belo Horizonte, 08 dez. 2017. Disponível em: http://www.siam.mg.gov.br/sla/download.pdf?idNorma= 45558. Acesso em: 10 ago. 2021.

COSTA, A.; MARTINS, R. A.; PEGADO, E. A. C. Análise técnica de estudos ambientais da atividade petrolífera onshore no Rio Grande do Norte. Holos, v.4, n.25, p.144-152, 2009.

FOGLIATTI, M.C.; FILIPPO, S.; GOUDARD, B. Avaliação de Impactos Ambientais: aplicação aos sistemas de transporte. Rio de Janeiro: Editora Interciência, 2004.

FONSECA, A.; RESENDE, L. Boas práticas de transparência, informatização e comunicação social no licenciamento ambiental brasileiro: uma análise comparada dos websites dos órgãos licenciadores estaduais. Engenharia Sanitária e Ambiental, v. 21, n.2, p. 295-306, 2016.

FONSECA, A.; SÁNCHEZ, L. E.; RIBEIRO, J. C. J. Reforming EIA systems: A critical review of proposals in Brazil. Environmental Impact Assessment Review, v.62, p.90-97, 2017.

GARBACCIO, G. L.; SIQUEIRA, L. N.; ANTUNES, P. B. Licenciamento ambiental: necessidade de simplificação. Justiça do Direito, v.32, n.3, p.562-582, 2018.

GLUCKER, A. N.; DRIESSEN, P. P. J.; KOLHOFF, A.; RUNHAAR, H. A. C. Public participation in environmental impact assessment: why, who and how? Environmental Impact Assessment Review, v.43, p.104-111, 2013.

IAIA. International Association for Impact Assessment. Principles of environmental impact assessment best practice. Fargo: IAIA, Special Publication v.1, 1999.
IEMA. Instituto Estadual do Ambiente. Instrução Normativa no 5, de 09 de agosto de 2010. Estabelece critérios para o licenciamento ambiental de estradas, rodovias e obras afins. Diário Oficial do Estado, Vitória, 10 ago. 2010. Disponível em: https://www.legisweb.com.br/legislacao/?id=127173. Acesso em: 13 mar. 2021.

IEMA. Instituto Estadual do Ambiente. Instrução Normativa n 014-N, de 07 de dezembro de 2016. Dispõe sobre o enquadramento das atividades potencialmente poluidoras e/ou degradadoras do meio ambiente com obrigatoriedade de licenciamento ambiental junto ao IEMA e sua classificação quanto a potencial poluidor e porte. Diário Oficial do Estado, Vitória, 12 dez. 2016. Disponível em: https://www.legisweb.com.br/legislacao/?id=333184.

Acesso em: 13 mar. 2021.

INEA. Instituto Estadual do Ambiente. Resolução n 32 , de 15 de abril de 2011. Estabelece os critérios para determinação do porte e potencial poluidor dos empreendimentos e atividades, para seu enquadramento nas classes do SLAM. Diário Oficial do Estado, Rio de Janeiro, 27 abr. 2011. Disponível em: http://www.inea.rj.gov.br/wp-

content/uploads/2019/09/RESOLU\%C3\%87\%C3\%83O -INEA-N\%C2\%BA-32-Crit\%C3\%A9rios-paradetermina\%C3\%A7\%C3\%A3o-do-porte-e-potencialpoluidor-dos-empreendimentos-e-atividades-nasclasses-do-SLAM.pdf. Acesso em: 16 jun. 2021.

INEA, Instituto Estadual do Ambiente. Resolução $n^{\circ} 52$, de 19 de março de 2012. Estabelece os novos códigos para $o$ enquadramento de empreendimentos e atividades poluidores ou utilizadores de recursos ambientais, bem como os capazes de causar degradação ambiental, sujeitos ao licenciamento ambiental. Diário Oficial do Estado, Rio de Janeiro, 22 mar. 2012. Disponível em: http://www.inea.rj.gov.br/wpcontent/uploads/2019/08/RESOLU\%C3\%87\%C3\%83O -INEA-N\%C2\%BA-52-Estabelece-novosc\%C3\%B3digos-para-enquadramento-deempreendimentos-e-atividades-poluidoras.pdf. Acesso em: 16 jun. 2021.

INEA. Instituto Estadual do Ambiente. Conselhos municipais de meio ambiente: orientações para implementação. Rio de Janeiro: INEA, 2015.

JONES, M.; MORRISON-SAUNDERS, A. Making sense of significance in environmental impact assessment. Impact Assessment and Project Appraisal, v.34, n.1, p.87-93, 2016.

LIMA, M. I. L. S.; REI, F. 40 anos de licenciamento ambiental: um reexame necessário. Revista de Direito Econômico e Socioambiental, v.8, n.2, p.378-410, 2017. 
MINAS GERAIS. Decreto nํ 47.383, de 02 de março de 2018. Estabelece normas para licenciamento ambiental, tipifica e classifica infrações às normas de proteção ao meio ambiente e aos recursos hídricos e estabelece procedimentos administrativos de fiscalização e aplicação das penalidades. Diário Oficial do Estado, Belo Horizonte, 03 mar. 2018. Disponível em: http://siam.mg.gov.br/sla/download.pdf?idNorma=4591 8. Acesso em: 10 ago. 2021.

MMA. Ministério do Meio Ambiente. Procedimentos de Licenciamento Ambiental do Brasil. Brasília: MMA, 2016. 544 p.

MMA. Ministério do Meio Ambiente. Procedimentos de Licenciamento Ambiental na Bahia. 2018. Disponível em:

http://pnla.mma.gov.br/images/2018/08/Procedimentosde-Licencamento-Ambiental-BAHIA-BA.pdf. Acesso em: 14 mar. 2021.

MOREIRA, I. V. D. Avaliação de Impacto Ambiental AIA. Rio de Janeiro: FEEMA, 1985.

OLIVEIRA, F. S. D.; PRADO FILHO, J. F.; ROCHA, C. F.; FONSECA, A. Licenciamento ambiental simplificado na região sudeste brasileira: conceitos, procedimentos e implicações. Desenvolvimento e Meio Ambiente, v.38, p.461-479, 2016.

RAJARAM, T.; DAS, A. Screening for EIA in India: Enhancing effectiveness through ecological carrying capacity approach. Journal of Environmental Management, v.92, p.140-148, 2011.

RIO GRANDE DO SUL. Li no 15.434, de 9 de janeiro de 2020.Institui o Código Estadual do Meio Ambiente do Estado do Rio Grande do Sul. Diário Oficial do Estado, Porto Alegre, 10 jan. 2020. Disponível em: https://leisestaduais.com.br/rs/lei-ordinaria-n-154342020-rio-grande-do-sul-institui-o-codigo-estadual-domeio-ambiente-do-estado-do-rio-grande-do-sul. Acesso em: 10 ago. 2021.

ROCHA, C. P. F.; FONSECA, A. Simulations of EIA screening across jurisdictions: exposing the case for harmonic criteria? Impact Assessment and Project Appraisal, 2017.

SÁNCHEZ, L. E. Avaliação de impacto ambiental de empreendimentos rodoviários e reassentamento humano. In: Relatório Técnico de consultoria especializada em avaliação de impacto ambiental em rodovias e reassentamento urbano. São Paulo: Secretaria dos Transportes, 2000.

SÁNCHEZ, L. E. Avaliação de Impacto Ambiental: conceitos e métodos. 3. ed. São Paulo: Oficina de Textos, 2020. 496p.

SANTOS, I. D. C. A avaliação de Impacto Ambiental e a responsabilidade do Brasil diante da degradação ao meio ambiente. Interfaces Científicas, v.1, n.2, p.6774, 2013.

SANTOS, P. F.; BORGES, L. A. C. 30 anos em 30 dias: a desconstrução do licenciamento ambiental participativo em Minas Gerais. Sociedade \& Natureza, v. 29, n.2, p.323-336, 2017.

SIMONETTI, H. Estudo de Impactos Ambientais Gerados pelas Rodovias: sistematização do processo de elaboração de EIA/RIMA. 2010. 55 f. Trabalho de Diplomação (Graduação em Engenharia Civil) Universidade Federal do Rio Grande do Sul, Porto Alegre, Rio Grande do Sul, 2010.

SIPPE R. Criteria and standards for assessing significant impact. In: PETTS, J. Handbook of environmental impact assessment. Volume 1: environmental impact assessment: process, methods and potential. Oxford: Blackwell Science, 1999. p.74-92.

SNELLEN, I.; THAENS, M.; DONK, W.V.D. Public administration in the information age: Revisited. Amsterdam: IOS Press, 2012. 308p.

WOOD, G.; BECKER, J. Discretionary judgement in local planning authority decision making: screening development proposals for environmental impact assessment. Journal of Environmental Planning and Management, v.48, n.3, p.349-371, 2005. 